\title{
A study on the perinatal outcome in cases of oligohydramnios
}

\author{
Pawanpreet Kaur*, Deepak A. Desai, Aartee Taraiya
}

Department of Obstetrics \& Gynaecology, SBKS Medical Institute and Research Centre, Vadodara, Gujarat, India

Received: 28 October 2015

Accepted: 15 December 2015

*Correspondence:

Dr. Pawanpreet Kaur,

E-mail: drpawskaur@gmail.com

Copyright: (C) the author(s), publisher and licensee Medip Academy. This is an open-access article distributed under the terms of the Creative Commons Attribution Non-Commercial License, which permits unrestricted non-commercial use, distribution, and reproduction in any medium, provided the original work is properly cited.

\begin{abstract}
Background: Amniotic fluid has an important role in the fetal growth and development. It provides the fetus, with a protective low resistance environment which is suitable for the growth and development. With normal amount of amniotic fluid index ranging from 5 to $24 \mathrm{cms}$, Amniotic fluid index of $<5 \mathrm{~cm}$ defines oligohydramnios as, originally described by Phelan et $\mathrm{al}^{1}$. Many studies show that oligohydramnios is associated with variety of ominous pregnancy outcomes, such as fetal distress, low birth weight, increased incidence of caesarean section, higher perinatal morbidity, and perinatal mortality. Since, these disorders of liquor amnii has a significant impact on pregnancy and fetus, it prompted us to carry out this study with sincere efforts to find out its effect on pregnancy outcome.

Methods: The study was done in Dhiraj Hospital in Obstetrics and Gynecology department. The study duration was period of 18 months from February 2014 to July 2015. It was a prospective study, comprising of patients, who had reported to hospital for regular antenatal visits. The study group was taken on sole criteria of AFI $<5 \mathrm{cms}$. It is considered as a contributing factor for intranatal and perinatal morbidity. To prove our point, in control group, patients with AFI $>5 \mathrm{cms}$ were taken. AFI $>10 \mathrm{cms}$ was considered to be normal. Various outcome measures recorded were, induced Vs spontaneous labor, gestational age at delivery, nature of amniotic fluid, FHR tracings, mode of delivery, indication for cesarean section or instrumental delivery Apgar score at one minute and five minutes, birth weight, admission to neonatal intensive care unit, perinatal morbidity and perinatal mortality.

Results: Normal quantity of liquor amnii is essential for normal and successful outcome of pregnancy, as it provides a safe milieu interior for the foetus in utero. Deprivation of required quantity, will adversely affect the neonatal outcome. Oligohydramnios, in itself is enough to cause such damage, by creating chronic hypoxic situation.

Conclusions: The fetal morbidity and mortality increases if additional antenatal complications of preeclampsia and post-term pregnancy are present along with oligohyrdramnios.
\end{abstract}

Keywords: Oligohydramnios, Perinatal outcome

\section{INTRODUCTION}

Amniotic fluid has an important role in the fetal growth and development. It provides the fetus, with a protective low resistance environment which is suitable for the growth and development. It provides a cushion, against the constricting confines of the gravid uterus and allowing the fetus, room for the movement and growth, protecting it from external trauma. It also has a role in maintaining the fetal body temperature, and plays a part in the homeostasis of fluid. By permitting extension of the limbs, it prevents joint contractures. It prevents compression of the umbilical cord, and thus protects the fetus from vascular and nutritional compromise.

The abnormalities of the fluid volume can thus, interfere directly with fetal development or provides an indirect sign of underlying disorder, such as fetal hypoxia, neural tube defect or gastro intestinal obstruction. 
In the past, the discussions of amniotic fluid volume were limited to observations of the quantity of fluid, released after rupture of membranes. The occurrence of thick meconium or fetal distress, in postdated pregnancies, for example, was attributed vaguely for placental insufficiency.

However, the importance of amniotic fluid volume, as an indicator of fetal status, was appreciated only recently.

Before the advent of ultrasound, clinicians had to rely on abdominal palpation, and fundal measurements, to detect abnormal fluid volume. The condition is usually severe, when oligohydramnios or polyhydramnios is detected by clinical examination. With the development of ultrasound imaging, the amniotic fluid volume assessment has progressed from a stage of subjective impression, to the present state, in which almost accurate judgments of fetal conditions can be based on reproducible measurements.

In present practice, a semi quantitative amniotic fluid volume assessment, during routine ultrasound examination, and antepartum testing, has become the standard of care.

The purpose of taking group of women, with oligohydramnios at term pregnancies, is to compare the etiology, management and the outcome being different in late onset oligohydramnios against early onset oligohydramnios.

With normal amount of amniotic fluid index ranging from 5 to $24 \mathrm{cms}$, Amniotic fluid index of $<5 \mathrm{~cm}$ defines oligohydramnios as, originally described by Phelan et al. ${ }^{1}$ Many studies show that oligohydramnios is associated with variety of ominous pregnancy outcomes, such as fetal distress, low birth weight, increased incidence of caesarean section, higher perinatal morbidity, and perinatal mortality.

These disorders may result from abnormal fetal or maternal conditions and, conversely, may be responsible for alterations of fetal well-being as well.

Since, these disorders of liquor amnii has a significant impact on pregnancy and fetus, it prompted us to carry out this study with sincere efforts to find out its effect on pregnancy outcome.

\section{Oligohydramnios}

An amniotic fluid volume, more than the two standard deviation, below the mean for specific gestational age, or volume reduced below the $5^{\text {th }}$ percentile, for particular gestational age, would define oligohydramnios. Based on this definition, volume less than $300 \mathrm{ml}$ at term would constitute oligohydramnios. In some instances, the amniotic fluid may be reduced to only few $\mathrm{ml}$ or viscid fluid.
The incidence of oligohydramnios varies depending on which definition is used, with a general reporting rate between $1-3 \% .^{2}$ When women undergoing antepartum testing for high-risk pregnancy conditions are examined, the incidence of oligohydramnios is much higher $(19-20 \%)$, as would be expected. This is primarily due to the underlying maternal or fetal indication for the antepartum testing. ${ }^{3}$

Table 1: Various authors have used different cut off values, for diagnosis of oligohydramnios.

\begin{tabular}{|c|c|c|}
\hline References & Technique & Definitions \\
\hline $\begin{array}{l}\text { Manning et } \\
\mathrm{al}^{4}\end{array}$ & USG & $\mathrm{MVP}<1 \mathrm{~cm}$ \\
\hline $\begin{array}{l}\text { Halpervin et } \\
\mathrm{al}^{5}\end{array}$ & USG & $\mathrm{MVP}<3 \mathrm{~cm}$ \\
\hline 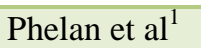 & USG & AFI $5 \mathrm{~cm}$ \\
\hline Brace ,Wolf ${ }^{6}$ & $\begin{array}{l}\text { Direct / Dye } \\
\text { dilutions }\end{array}$ & $318 \mathrm{ml}$ \\
\hline $\begin{array}{l}\text { Manning et } \\
\mathrm{al}^{7}\end{array}$ & USG & $\mathrm{MVP}<2 \mathrm{~cm}$ \\
\hline Moore et $\mathrm{al}^{8}$ & USG & $\begin{array}{l}\text { MVP }<5^{\text {th }} \\
\text { percentile }\end{array}$ \\
\hline Jeng et $\mathrm{al}^{9}$ & USG & AFI $8 \mathrm{~cm}$ \\
\hline $\begin{array}{l}\text { Magann et } \\
\mathrm{al}^{10}\end{array}$ & Dye dilution & $500 \mathrm{ml}$ \\
\hline $\begin{array}{l}\text { Magann et } \\
\mathrm{al}^{10}\end{array}$ & USG & $\begin{array}{l}2 \text { diameter pocket } \\
\text { vertical } \mathrm{x} \\
\text { horizontal }<15 \mathrm{~cm}\end{array}$ \\
\hline $\begin{array}{l}\text { Horsanger et } \\
\mathrm{al}^{11}\end{array}$ & Dye dilution & $200 \mathrm{ml}$ \\
\hline
\end{tabular}

However, in recent years AFI is used by most of the authors. Between 36-42 weeks, Phelan et al defined oligohydramnios as AFI less than or equal to $5 \mathrm{~cm}$ and borderline oligohydramnios as AFI between 5 and $8 \mathrm{~cm}^{1}$

The likelihood AFI $<5 \mathrm{~cm}$ is $2.4 \%$ and in pregnancies more than 40 weeks the incidence may be more than $12 \%$ as the amniotic fluid volume declines progressively, after 41 weeks of gestation.

\section{METHODS}

The study was done in Dhiraj Hospital in Obstetrics and Gynecology department. The study duration was 18 months from February 2014 to July 2015. It was a prospective study, comprising of patients, who had reported to hospital for regular antenatal visits. The Main aim and objective as follows.

1. To study the perinatal outcome in oligohydramnios $(\mathrm{AFI}<5)$ at term.

2. To evaluate the value of AFI in predicting the subsequent fetal distress and caesarean delivery.

3. To assess whether ante-partum oligohydramnios is associated with adverse perinatal outcome. 


\section{Inclusion criteria}

1. Pregnant women with Thirty seven completed weeks of gestation.

2. Intact membranes.

3. AFI assessed by ultrasound of $<5 \mathrm{~cm}$.

4. Singleton pregnancy with cephalic presentation.

5. Patient should have delivered during same hospitalization when AFI was determined.

\section{Exclusion criteria}

1. Patients with gestational age less than 37 weeks or more than 42 weeks of gestation.

2. Patients with known fetal malformations.

3. Patients with Ruptured membranes.

4. Multifocal pregnancy.

5. Intrauterine death of the fetus.

The study group was taken on sole criteria of AFI $<5 \mathrm{cms}$. It is considered as a contributing factor for intranatal and perinatal morbidity. To prove our point, in control group, patients with AFI $>5 \mathrm{cms}$ were taken. AFI $>10 \mathrm{cms}$ was considered to be normal.

Informed written consent for participation in this study was taken from all patients fulfilling the inclusion and exclusion criteria. In all these patients, thorough history was taken. General physical examination and systemic examination including a detailed obstetric examination was performed. Relevant investigations were performed and managed accordingly.

Patients were examined in the Radiology Department of the Institute. The gestational age of the study population at the time of the ultrasonographic examination was 37 completed weeks. The pregnancies with fetal malformations were also excluded from the study except for the deformities that can be caused by oligohydramnios like CTEV.

Each ultrasonographic examination was performed transabdominally with real-time equipment and a $3.5 \mathrm{MHz}$ linear-array transducer (Siemens Sonoline SL-2 ultrasound scanner). The patients were placed in the supine position. Standard fetal biometry was obtained.

Using landmark on the maternal abdomen, the uterus was divided into four quadrants - right and left halves by the linear nigra, and the upper and lower halves by an imaginary line across the midway between the fundus of the uterus and symphysis pubis. The linear transducer head was placed on the abdomen along the mother's longitudinal axis and held perpendicular to the floor in the sagittal plane. The maximum vertical dimension of the largest fluid pocket in each quadrant was measured in millimeters. The measurements obtained from each quadrant were summed to form the amniotic fluid index (AFI). The identified pocket was considered clear when umbilical cord and other small parts of the fetus are absent.

The management protocol was similar in both study group and control group. Those women who had high risk factors like preeclampsia, post-term pregnancy and non-reactive NST, were induced using dinoprostone gel $\left(\mathrm{PGE}_{2}\right)$ or oxytocin. Women with no other risk factors were allowed for spontaneous onset of labour and NST was done. All were monitored by continuous electronic fetal monitoring in labour. The nature of amniotic fluid noted at artificial rupture of membrane which was done in women with non-reassuring fetal heart rate and was classified as clear, thin meconium stained liquor and thick meconium stained liquor. Those who developed significant variable decelerations and repetitive late decelerations or other ominous FHR pattern with or without meconium stained liquor which persisted inspite of corrective measures like change in maternal position, hydration, $\mathrm{O}_{2}$ inhalation and stopping oxytocin were delivered by LSCS or forceps delivery. All newborns were attended by neonatologists and endotracheal intubation was done in presence of thick meconium stained amniotic fluid.

Various outcome measures recorded were, induced versus spontaneous labor, gestational age at delivery, nature of amniotic fluid, FHR tracings, mode of delivery, indication for cesarean section or instrumental delivery Apgar score at one minute and five minutes, birth weight, admission to neonatal intensive care unit, perinatal morbidity and perinatal mortality.

\section{Statistical methods}

The results were recorded and tabulated. The results were statistically analyzed using parameters like mean, standard deviation and chi square test. In addition, epidemiological parameters like sensitivity, specificity, positive predictive value, negative predictive value were used.

\section{RESULTS}

This study is performed in 100 pregnant women with amniotic fluid index of $<5 \mathrm{~cm}$ and has completed 37 weeks of gestation and is compared with 100 pregnant women with amniotic fluid index between $5 \mathrm{~cm}$ and 20 $\mathrm{cm}$. These groups were similar with regard to antepartum variables i.e., maternal age gravidity, parity, gestational age and antenatal complications.

The age distribution is shown in Table 2. The mean age for study group was $23.2 \pm 3.4$ years and that of control group was $22.7 \pm 3.2$ years. There was no difference in the mean age between two groups statistically. 
Table 2: Age distribution.

\begin{tabular}{|ccc|}
\hline Age (years) & Study group & Control group \\
\hline $18-20$ & 28 & 28 \\
\hline $21-25$ & 50 & 58 \\
\hline $26-30$ & 22 & 14 \\
\hline Total & 100 & 100 \\
\hline
\end{tabular}

Table 3: Gravidity distribution.

\begin{tabular}{|lllllll|}
\hline \multirow{2}{*}{ Gravidity } & \multicolumn{2}{c}{ Gravida } & & & & Total \\
\hline Study Group & 1 & 2 & 3 & 4 & 5 & \\
\hline Control Group & 50 & 24 & 22 & 4 & 0 & 100 \\
\hline
\end{tabular}

Table 4: Parity distribution.

\begin{tabular}{|c|c|c|c|c|c|}
\hline \multirow{2}{*}{ Parity } & \multirow{2}{*}{ Nullipara } & \multicolumn{3}{|c|}{ Para } & \multirow{2}{*}{ Total } \\
\hline & & 1 & 2 & 3 & \\
\hline Study Group & 60 & 30 & 8 & 2 & 100 \\
\hline Control Group & 62 & 24 & 8 & 6 & 100 \\
\hline
\end{tabular}

The distribution of gravidity and parity are shown in Table 3 and 4 respectively. The mean gravidity was 0.83 and 0.75 and mean parity was 0.52 and 0.58 respectively for cases and controls.
Table 5: Distribution of gestational age.

\begin{tabular}{|ccc|}
\hline $\begin{array}{c}\text { Gestational age } \\
\text { (weeks) }\end{array}$ & $\begin{array}{c}\text { Study } \\
\text { group }\end{array}$ & $\begin{array}{c}\text { Control } \\
\text { group }\end{array}$ \\
\hline 37 & 18 & 12 \\
\hline 38 & 14 & 14 \\
\hline 39 & 22 & 20 \\
\hline 40 & 20 & 24 \\
\hline 41 & 16 & 20 \\
\hline 42 & 10 & 10 \\
\hline Total & 100 & 100 \\
\hline
\end{tabular}

The mean gestational age was $39.3 \pm 1.58$ weeks for study group and $39.56 \pm 1.5$ weeks for control group which was similar Table 5.

Various antenatal complications that were noted include preeclampsia, post term pregnancy (42 completed weeks), and Abruptio placenta. The diagnosis of Abruptio placenta was made in two cases following delivery by noting retro placental clot. The situations are shown in Table 6 .

The remaining 54 patients of both study group and control group had no such antenatal maternal complications. Thus $46 \%$ of study group was belonging to high risk category. The occurrences of preeclampsia and post term pregnancies were similar in control group as well.

Table 6: Antenatal complications.

\begin{tabular}{|lllll|}
\hline & Study group & & \multicolumn{2}{c|}{ Control group } \\
\hline Antenatal complications & Number of cases & Percentage & Number of control & Percentage \\
\hline Mild preeclampsia & 22 & $22 \%$ & 22 & $22 \%$ \\
\hline Severe preeclampsia & 10 & $10 \%$ & 10 & $10 \%$ \\
\hline Post term pregnancy & 10 & $10 \%$ & 8 & $8 \%$ \\
\hline Abruptio placentae & 2 & $2 \%$ & 2 & $2 \%$ \\
\hline Post-term pregnancy with preeclampsia & 2 & $2 \%$ & 2 & $2 \%$ \\
\hline
\end{tabular}

Table 7: Distribution of antenatal complications according to parity.

\begin{tabular}{|lcccccc|}
\hline Parity & \multicolumn{2}{c}{ Study group } & \multicolumn{2}{c}{ Control group } \\
& $\begin{array}{c}\text { Mild } \\
\text { Preeclampsia }\end{array}$ & $\begin{array}{c}\text { Severe } \\
\text { Preeclampsia }\end{array}$ & Post term & $\begin{array}{c}\text { Mild } \\
\text { Preeclampsia }\end{array}$ & $\begin{array}{c}\text { Severe } \\
\text { Preeclampsia }\end{array}$ & Post term \\
\hline Nullipara & 18 & 10 & 10 & 20 & 10 & 6 \\
\hline Para 1 & 4 & 0 & 0 & 2 & 0 & 0 \\
\hline Para 2 & 0 & 0 & 0 & 0 & 0 & 0 \\
\hline Para 3 & 0 & 0 & 0 & 0 & 10 & 8 \\
\hline Total & 22 & 10 & 10 & 22 & 0 & 0 \\
\hline
\end{tabular}

Two cases in study group who had Abruptio were primi and two cases who had post-term with mild preeclampsia were Para-1.
A.F.I. was always $\geq 6$ in all case of control group, as it is an inclusion criterion for control group Table 7. 
The amniotic fluid index was measured by four quadrant amniotic fluid volume assessment technique. The mean AFI for study group was $3.6 \pm 0.9 \mathrm{~cm}$ and for control group was $9.4 \pm 3.07 \mathrm{~cm}$. The distribution of AFI in both groups are shown in Table 8 and 9.

Table 8: Distribution of amniotic fluid index (AFI)study group.

\begin{tabular}{|lll|}
\hline AFI in cm & Number & Percentage \\
\hline $2-3$ & 34 & $34 \%$ \\
\hline $3.1-4$ & 26 & $26 \%$ \\
\hline $4.1-5$ & 40 & $40 \%$ \\
\hline Total & 100 & $100 \%$ \\
\hline
\end{tabular}

Table 9: Distribution of amniotic fluid index (AFI) control group.

\begin{tabular}{|lll|}
\hline AFI in cm & Number & Percentage \\
\hline $6-8$ & 38 & $38 \%$ \\
\hline $8.1-11$ & 27 & $27 \%$ \\
\hline $11.1-14$ & 29 & $29 \%$ \\
\hline $14.1-17$ & 6 & $6 \%$ \\
\hline Total & 100 & $100 \%$ \\
\hline
\end{tabular}

The outcome parameter analysis include non-stress test, fetal heart rate decelerations on CTG, colour and viscosity of amniotic fluid, induction rate, mode of delivery, incidence of LSCS and instrumental delivery for fetal distress, Apgar score at 1 minute and 5 minutes, birth weight, admission to neonatal ward and perinatal morbidity and mortality.

Table 10: Non stress test pattern.

\begin{tabular}{|lllll|}
\hline NST & Study group & & Control group & Percentage \\
\hline & Number & Percentage & Number & $80 \%$ \\
\hline Reactive & 62 & $62 \%$ & 80 & $20 \%$ \\
\hline Non-Reactive & 38 & $38 \%$ & 20 & $100 \%$ \\
\hline Total & 100 & $100 \%$ & 100 & 100 \\
\hline
\end{tabular}

$\left(\mathrm{X}^{2}=7.86\right.$, Dof $=1, \mathrm{P}<0.05$ - significant $)$.

Table 11: Comparison of non-stress test with antenatal complications.

\begin{tabular}{|c|c|c|c|c|c|c|}
\hline \multirow{3}{*}{$\begin{array}{l}\text { Non stress } \\
\text { test }\end{array}$} & \multicolumn{3}{|c|}{ Study group } & \multicolumn{3}{|c|}{ Control group } \\
\hline & Mild & Severe & Post Term & Mild & Severe & Post Term \\
\hline & Preeclampsia & Preeclampsia & Pregnancy & Preeclampsia & Preeclampsia & Pregnancy \\
\hline Non-reactive & 6 & 10 & 8 & 0 & 10 & 6 \\
\hline Reactive & 14 & 0 & 0 & 22 & 0 & 2 \\
\hline & \multicolumn{3}{|c|}{ Chi square: $19.9, \mathrm{p}$ value: 0.0001} & \multicolumn{3}{|c|}{ Chi square: $33.7, \mathrm{p}$ value: 0.0001} \\
\hline
\end{tabular}

The non- stress test was non- reactive in 38 (38\%) women with AFI $\leq 5 \mathrm{~cm}$ compared to only 20 (20\%) in control group (Table 10). There was significant difference between two groups in occurrence of nonreactive and reactive NST pattern $(\mathrm{P}<0.05)$.

There were 14 cases of study group, who had preeclampsia with reactive NST. This could be due to the reason, that the damage to placental circulation was not extensive. So, despite AFI $<5 \mathrm{cms}$, the non-stress test was reactive.

Most common FHR abnormality included variable decelerations which was considered significant if it was below $70 \mathrm{bpm}$ persisting for $>60 \mathrm{sec}$. The significant variable decelerations ( $<70 \mathrm{bpm}$ for $>60 \mathrm{sec}$ ) was noted in 40 women $(40 \%)$ and repetitive late deceleration in 20 $(20 \%)$ of women of study group. In the control group, 18 women developed variable decelerations and 12 women had late deceleration. However, these ominous FHR were seen in those women of control group who had an AFI in the lower range. There was no significant difference in two groups in occurrence of FHR decelerations statistically $(\mathrm{P}=0.53)$.

In study group, 2 cases with Abruptio also had late decelerations. Therefore, the cases with antenatal complications had more fetal heart decelerations. The data was statistically significant $(\mathrm{P}=0.0005)$.

Late deceleration suggests an additional reason for fetal stress, like prolonged hypoxia, persistent increased intrauterine pressure, due to uncoordinated contractions.

Remaining of 20 cases in study group and 2 cases in control group with fetal heart decelerations had no antenatal complications. The amniotic fluid was thick meconium stained in $48(48 \%)$ and thin meconium stained in $12(12 \%)$ women in study group. In control group, only 20 (20\%) women had thick meconium stained amniotic fluid and $6(6 \%)$ had thin meconium 
stained amniotic fluid. The difference in occurrence of meconium stained amniotic fluid between two groups was statistically significant. Passage of thick meconium suggests severity due to prolonged hypoxia.
Induction of labour was done in $54(54 \%)$ women with AFI $<5 \mathrm{~cm}$ and $24(24 \%)$ women with AFI $>5 \mathrm{~cm}$. The difference between two groups in this category was statistically significant $(\mathrm{P}<0.0001)$.

Table 12: Occurrence of variable decelerations and late decelerations.

\begin{tabular}{|lllll|}
\hline FHR pattern & Study group & & Control group \\
\hline & Number* & Percentage* & Number\# & Percentage\# \\
\hline Variable decelerations & 40 & $40 \%$ & 18 & $18 \%$ \\
\hline Late decelerations & 20 & $20 \%$ & 12 & $12 \%$ \\
\hline Total decelerations & 60 & $60 \%$ & 30 & $30 \%$ \\
\hline
\end{tabular}

Chi Square $=0.38$, Dof $=1, \mathrm{P}=0.53$ - Non Significant); (of total No. of Cases); (of total No. of Controls).

Table 13: Comparison of deceleration with antenatal complications.

\begin{tabular}{|c|c|c|c|c|c|c|}
\hline \multirow[b]{2}{*}{ FHR pattern } & \multicolumn{3}{|c|}{ Study group } & \multicolumn{2}{|c|}{ Control group } & \\
\hline & $\begin{array}{l}\text { Mild } \\
\text { preeclampsia }\end{array}$ & $\begin{array}{l}\text { Severe } \\
\text { Preeclampsia }\end{array}$ & $\begin{array}{l}\text { Post Term } \\
\text { Pregnancy }\end{array}$ & $\begin{array}{l}\text { Mild } \\
\text { Preeclampsia }\end{array}$ & $\begin{array}{l}\text { Severe } \\
\text { Preeclampsia }\end{array}$ & $\begin{array}{l}\text { Post Term } \\
\text { Pregnancy }\end{array}$ \\
\hline Late deceleration & 10 & 0 & 0 & 6 & 2 & 2 \\
\hline Variable deceleration & 8 & 10 & 10 & 4 & 8 & 8 \\
\hline
\end{tabular}

Table 14: Colour of amniotic fluid.

\begin{tabular}{|lllll|}
\hline Amniotic Fluid & \multicolumn{2}{l}{ Study group } & Control group & \\
& Number & Percentage & Number & Percentage \\
\hline Clear & 40 & $40 \%$ & 74 & $74 \%$ \\
\hline Thin meconium & 12 & $12 \%$ & 6 & $6 \%$ \\
\hline Thick meconium & 48 & $48 \%$ & 20 & $20 \%$ \\
\hline Total & 100 & $100 \%$ & 100 & $100 \%$ \\
\hline
\end{tabular}

Table 15: Induced Versus Spontaneous labour.

\begin{tabular}{|c|c|c|c|c|}
\hline Labour & Stt & & Cont & \\
\hline & Number & Percentage & Number & Percentage \\
\hline Induced & 54 & $54 \%$ & 24 & $24 \%$ \\
\hline Spontaneous & 46 & $46 \%$ & 76 & $76 \%$ \\
\hline Total & 100 & $100 \%$ & 100 & $100 \%$ \\
\hline
\end{tabular}

Table 16: Mode of delivery (all cases).

\begin{tabular}{|lllll|}
\hline Mode of delivery & \multicolumn{2}{c|}{ Study group } & Control group & Number \\
\hline & Number & Percentage & 72 & $72 \%$ \\
\hline Normal vaginal delivery & 40 & $40 \%$ & 22 & $22 \%$ \\
\hline LSCS & 48 & $48 \%$ & 6 & $6 \%$ \\
\hline Outlet Forceps delivery & 12 & $12 \%$ & 100 & $100 \%$ \\
\hline Total & 100 & $100 \%$ & 100 & \\
\hline
\end{tabular}

In study group, 30 cases were induced with cerviprime gel and 24 with oxytocin drip. In control group, 14 cases were induced with cerviprime gel and 10 with oxytocin drip. The decision for induction or allowing for spontaneous labour was made depending upon AFI, gestational age, and presence of complications like 
preeclampsia, post-term pregnancy, non-reactive NST, and position \& state of cervix, i.e. cervical score.

In study group, 54 patients were induced, of which 22 delivered vaginally and 32 needed LSCS. Out of these 32 cases, 29 had meconium stained liquor and 3 had fetal distress. Of these 54 cases, who were induced, 24 had preeclampsia, 8 were post-term, rest 22 were solely with $\mathrm{AFI}<5$.

Table 17: Comparison of mode of delivery with meconium stained liquor.

\begin{tabular}{|lllllll|}
\hline $\begin{array}{l}\text { Mode of } \\
\text { delivery }\end{array}$ & \multicolumn{2}{c}{ Study group } & Control group & & \\
\hline FTND & 26 & Thick meconium & Thin meconium & Clear & Thick meconium & Thin meconium \\
\hline LSCS & 14 & 34 & 0 & 64 & 4 & 4 \\
\hline Outlet forceps & 2 & 0 & 2 & 6 & 16 & 0 \\
\hline
\end{tabular}

Table 18: Interventions in study and control group.

\begin{tabular}{|lllll|}
\hline Interventions & Study group & \multicolumn{2}{c|}{ Control group } \\
\hline & Number* & Percentage* & Number\# & Percentage\# \\
\hline LSCS & 48 & $48 \%$ & 22 & $22 \%$ \\
\hline Instrumental delivery (Outlet Forceps) & 12 & $12 \%$ & 6 & $6 \%$ \\
\hline Total Interventions & 60 & $60 \%$ & 28 & $28 \%$ \\
\hline
\end{tabular}

$\left(\mathrm{X}^{2}=0.023\right.$, Dof $\left.=1, \mathrm{p}=0.87\right) ;$ * (of total No. of Cases); (of total No. of controls).

Table 19: Interventions Due To Fetal Distress.

\begin{tabular}{|lllll|}
\hline Interventions & Study group & & Control group \\
\hline LSCS & Number* & Percentage* & Number\# & Percentage\# \\
\hline Outlet Forceps & 48 & $48 \%$ & 12 & $12 \%$ \\
\hline
\end{tabular}

$\left(\mathrm{X}^{2}=7.086\right.$, Dof $\left.=1, \mathrm{p}=0.0078\right) ;$ * (of total No. of Cases); \# (of total No. of controls).

In control group, 24 patients were induced, of which 4 delivered vaginally and 20 needed LSCS. Out of these 20 cases, 26 had meconium stained liquor and 4 had fetal distress. Of these 24 cases, who were induced, 14 had preeclampsia, 8 were post-term, and rest 2 did not have good uterine contractions.

Table 20: Amniotic fluid index as a screening test.

\begin{tabular}{|lcc|}
\hline Groups & LSCS & Vaginal delivery \\
\hline $\begin{array}{l}\text { AFI } \leq 5 \\
\text { (Study group) }\end{array}$ & $48(a)$ & $52(b)$ \\
\hline $\begin{array}{l}\text { AFI }>5 \\
\text { (Control group) }\end{array}$ & 22(c) & $78(d)$ \\
\hline
\end{tabular}

Outlet forceps deliveries were to cut down the duration of second stage, and thereby reducing the time of exposure to detrimental situation, as cervix was fully dilated in 9 cases and nearly fully dilated in 3 cases, which progressed to full dilatation within a short time. All these cases had progressed to a stage to be "too late" for a Cesarean Section. Of 12 cases of the study group, 4 required neonatal care. None of the cases of control group, required neonatal care.
$48(48 \%)$ of them were delivered by cesarean section and $12(12 \%)$ of them by forceps delivery. The corresponding values for control group were $22(22 \%)$ and $6(6 \%)$ respectively as per Table 12 and 13 . The difference was statistically non-significant $(\mathrm{P}=0.87)$.

In our study cases, LSCS due to fetal distress was in $48 \%$, as against LSCS is $12 \%$ due to fetal distress, in control group. This higher incidence in study group was due to association of Oligohydramnios, as a yet another factor to increase intrauterine stress and cause fetal distress. This study shows that oligohydramnios $(<5 \mathrm{~cm})$, as a factor, is responsible for a higher incidence for intrapartum fetal stress, that calls for help, in such cases, as LSCS.

The determination of AFI $<5 \mathrm{~cm}$ as a screening test in predicting fetal distress during labor requiring LSCS, has a sensitivity of $68 \%$, specificity $60 \%$, positive predictive value $48 \%$ and negative predictive value of $78 \%$.

$$
\begin{aligned}
& \text { Sensitivity }=\frac{a}{a+c} * 100=\frac{48}{48+22} * 100=68 \% \\
& \text { Specificity }=\frac{d}{b+d} * 100=\frac{78}{52+78} * 100=60 \%
\end{aligned}
$$


Positive Predictive Value $=\frac{a}{a+b} * 100=\frac{48}{48+52} * 100=48 \%$ Negative Predictive Value $=\frac{d}{c+d} * 100=\frac{78}{22+78} * 100=78 \%$

A better sensitivity and negative predictive value makes it a good screening test.

The occurrence of cesarean section rate was high in oligohydramnios group when associated with nonreactive NST $(63.15 \%)$.

Table 21: LSCS for fetal distress in non-reactive NST.

\begin{tabular}{|lccc|}
\hline Groups & $\begin{array}{c}\text { Non- } \\
\text { reactive } \\
\text { NST }\end{array}$ & $\begin{array}{c}\text { LSCS for } \\
\text { fetal distress }\end{array}$ & Percentage \\
\hline $\begin{array}{l}\text { Study } \\
\text { group }\end{array}$ & 38 & 24 & $63.15 \%$ \\
\hline $\begin{array}{l}\text { Control } \\
\text { group }\end{array}$ & 20 & 10 & $50.00 \%$ \\
\hline
\end{tabular}

Even when the NST was reactive in oligohydramnios, $38.7 \%$ had LSCS. In this group, an additional factor was meconium stained liquor with fetal heart decelerations.
Table 22: LSCS for fetal distress in reactive non stress test.

\begin{tabular}{|lccc|}
\hline Groups & Reactive NST & LSCS & Percentage \\
\hline $\begin{array}{l}\text { Study } \\
\text { Group }\end{array}$ & 62 & 24 & $38.7 \%$ \\
\hline $\begin{array}{l}\text { Control } \\
\text { Group }\end{array}$ & 80 & 4 & $5 \%$ \\
\hline
\end{tabular}

Table 23: Apgar score $<7$.

\begin{tabular}{|lcccc|}
\hline Apgar & \multicolumn{2}{c|}{ Study Group } & \multicolumn{2}{c|}{ Control Group } \\
\cline { 2 - 5 } Score & No. & Percentage & No. & Percentage \\
\hline 1 minute & 41 & 41 & 32 & 32 \\
\hline 5 minutes & 40 & 40 & 12 & 12 \\
\hline
\end{tabular}

( Chi square $=0.576$, Dof $=1, \mathrm{p}$ value $=0.01-\mathrm{S})$.

Table 24: Birth weights.

\begin{tabular}{|lllll|}
\hline Weight & \multicolumn{2}{c}{ Study group } & \multicolumn{2}{c|}{ Control group } \\
\cline { 2 - 5 } & Number & Percentage & Number & Percentage \\
\hline $1.5-2$ & 12 & $12 \%$ & 0 & $0 \%$ \\
\hline $2.1-2.5$ & 48 & $48 \%$ & 28 & $28 \%$ \\
\hline $2.6-3$ & 26 & $26 \%$ & 48 & $48 \%$ \\
\hline $3.1-3.5$ & 10 & $10 \%$ & 24 & $24 \%$ \\
\hline$>3.5$ & 4 & $4 \%$ & 0 & $0 \%$ \\
\hline Total & 100 & $100 \%$ & 100 & $100 \%$ \\
\hline
\end{tabular}

Table 25: Comparison of low birth weight with pre-eclampsia.

\begin{tabular}{|lccccc|}
\hline \multicolumn{1}{|c}{ Pre-Eclampsia } & \multicolumn{2}{c}{ Low birth weight (study group) $(\leq 2.5 \mathrm{~kg})$} & \multicolumn{2}{c|}{ Low birth weight (control group) $(\leq 2.5 \mathrm{~kg})$} \\
& Number & Percentage & Number & Percentage \\
\hline Mild Pre-eclampsia & 8 & $8 \%$ & 4 & $4 \%$ \\
\hline Severe Pre-eclampsia & 6 & $6 \%$ & 10 & $10 \%$ \\
\hline
\end{tabular}

The mean Apgar score for study group was at 6.93 at 1 minute, and 8 at 5 minute. The mean Apgar score for women with AFI $>5 \mathrm{~cm}$ (control group) was 7.54 at 1 minute and 8.84 at $5 \mathrm{~min}$. The $5 \mathrm{~min}$ Apgar $<7$ was seen in $40 \%$ in study group and $12 \%$ in control group. The mean Apgar score was statistically significant and the difference in the occurrence of Apgar score $<7$ among study and control group was also statistically significant (Chi square value: 0.576 and $\mathrm{p}$ value: 0.01 ).

Reduced liquor is a known factor for intrauterine growth restriction. The inhibitive role may be aggravated by preeclampsia and hypertension.

In study group, 40 neonates of study group were admitted to neonatal intensive care unit for various morbidities like birth asphyxia, neonatal seizures and meconium aspiration. Only 12 (12\%) of control group were admitted to neonatal intensive care unit. The difference in the two groups was statistically significant $(\mathrm{P}<0.001)$.

Bilateral congenital talipes equino varus was present in 1 infant born to women with AFI $<5 \mathrm{~cm}$ and in none born to women with AFI $>5 \mathrm{~cm}$. This is said to be due to reduced intra uterine space, as it occurs in oligohydramnios.

In study group, out of the 40 neonatal admissions, 26 were associated with antenatal complications. Preeclampsia is known to have a poor neonatal outcome. The neonates were admitted for various reasons like birth asphyxia and meconium aspiration syndrome, respiratory distress syndrome. Rest 14 had no antenatal complications and the sole factor was AFI $<5 \mathrm{cms}$. 
Table 26: Admission to neonatal intensive care unit.

\begin{tabular}{|llll|}
\hline \multicolumn{2}{|l|}{ Study group } & \multicolumn{2}{l|}{ Control group } \\
\hline Number & Percentage & Number & Percentage \\
\hline 40 & $40 \%$ & 12 & $12 \%$ \\
\hline
\end{tabular}

$($ Chi Square $=20.37$, Dof $=1, p$ value $<0.001)$.

Table 27: Association of neonatal admissions with maternal complications.

\begin{tabular}{|lcc|}
\hline Antenatal & \multicolumn{2}{c|}{ Neonatal admissions } \\
complications & Study group & Control group \\
\hline Mild preeclampsia & 11 & 0 \\
\hline Severe preeclampsia & 9 & 8 \\
\hline Post term & 6 & 4 \\
\hline
\end{tabular}

Table 28: Neonatal deaths.

\begin{tabular}{|llll|}
\hline \multicolumn{2}{|l|}{ Study group } & \multicolumn{2}{l|}{ Control group } \\
\hline Number & Percentage & Number & Percentage \\
\hline 8 & $8 \%$ & 2 & $2 \%$ \\
\hline
\end{tabular}

$($ Chi square $=3.7$, Dof $=1, \mathrm{p}$ value $=0.0516-\mathrm{NS})$

There were 8 early neonatal deaths in study group and 2 early neonatal deaths in control group. The difference in the neonatal deaths was statistically non-significant between two groups $(\mathrm{P}=0.051)$. In study group, 6 neonates who died, the mode of delivery was LSCS and 2 neonates who died delivered vaginally. In control group, there were 2 neonatal deaths and their mode of delivery was LSCS.

The reasons of deaths in study group are as follows.

1. Four neonates died due to Meconium Aspiration Syndrome with Early Onset of Sepsis;

2. Two died due Severe Respiratory Distress Syndrome with IUGR.

3. Two due to Severe Birth Asphyxia.

The reasons of deaths in control group are two neonatal deaths were due to meconium aspiration syndrome with severe birth asphyxia. There was no maternal mortality in our study.

\section{DISCUSSION}

The results outcomes are compared to results of the other similar studies.

Post-term pregnancy was seen in $10 \%$ of women with AFI $<5 \mathrm{~cm}$ in present study compared to $15.38 \%$ and $25 \%$ women in study by Chandra $\mathrm{P}$ and Sriya $\mathrm{R}$ respectively. Hypertensive disorders cause chronic placental insufficiency and leads to oligohydramnios. In the oligohydramnios group, $32 \%$ had mild or severe preeclampsia compared to $38.46 \%$ and $31 \%$ of oligohydramnios group in study by Chandra $\mathrm{P}$ et al and Sriya $\mathrm{R}$ et al. Any cause of chronic placental insufficiency including chronic hypoxia can cause fetal growth restriction and oligohydramnios in term pregnancies.

Table 29: Comparison of antenatal complications.

\begin{tabular}{|lccc|}
\hline Complication & $\begin{array}{c}\text { Chandra } \\
\mathbf{P}^{12}\end{array}$ & $\begin{array}{c}\text { Sriya } \\
\mathbf{R}^{13}\end{array}$ & $\begin{array}{c}\text { Present } \\
\text { study }\end{array}$ \\
\hline $\begin{array}{l}\text { Hypertensive } \\
\text { disorders }\end{array}$ & $38.46 \%$ & $31.00 \%$ & $32 \%$ \\
\hline $\begin{array}{l}\text { Post term } \\
\text { pregnancy }\end{array}$ & $15.38 \%$ & $25.00 \%$ & $10 \%$ \\
\hline $\begin{array}{l}\text { Abruptio } \\
\text { Placenta }\end{array}$ & $7.69 \%$ & - & $2 \%$ \\
\hline
\end{tabular}

Table 30: Comparison non-reactive non stress tests.

\begin{tabular}{|c|c|}
\hline Studies & $\begin{array}{l}\text { Percentage of non- } \\
\text { reactive NST }\end{array}$ \\
\hline Kumar Petal $^{14}$ & $40 \%$ \\
\hline Chandra $\mathrm{P}$ et $\mathrm{al}^{12}$ & $69.23 \%$ \\
\hline Sriya $\mathrm{R}$ et al ${ }^{13}$ & $41.55 \%$ \\
\hline Present Study & $38 \%$ \\
\hline
\end{tabular}

The non-reactive non stress test rates are high in women with AFI $<5 \mathrm{~cm}$. The rate of non-reactive NST is $38 \%$ in present study and is comparable to that in similar studies (Table 30). The reason for a high incidence of $69 \%$ in Chandra's series is not elaborated by the author.

Table 31: Occurrence of thick meconium stained liquor.

\begin{tabular}{|ll|}
\hline Studies & $\begin{array}{l}\text { Occurrence of thick } \\
\text { meconium stained liquor } \\
\text { in percentage }\end{array}$ \\
\hline Rutherford et al $^{15}$ & $54 \%$ \\
\hline Chandra P et al $^{12}$ & $23.7 \%$ \\
\hline Sriya R et al & $38.88 \%$ \\
\hline Present Study & $48 \%$ \\
\hline
\end{tabular}

The occurrence of meconium stained amniotic fluid is high in women with AFI $<5 \mathrm{~cm}$. The thick meconium stained liquor was noted in $48 \%$ in study group in present study which is similar to other studies. In a study, by Grubb et al $99 \%$ of women with AFI $<5 \mathrm{~cm}$ and prolonged deceleration, had meconium stained liquor.

Out of these 48 cases with thick meconium, 20 had antenatal complication of preeclampsia. Rest of the cases with no antenatal complications also got meconium stained liquor, probably due to the intrauterine pressure that results in reduction of the placental blood supply leading to hypoxia and passage of meconium.

Various studies show different rates of LSCS for fetal distress in pregnant women with amniotic fluid index of $<5 \mathrm{~cm}$. The LSCS for fetal distress was done in $48 \%$ in 
present study which is compared with the situations in other studies in Table 32.

Table 32: LSCS for fetal distress.

\begin{tabular}{|c|c|}
\hline Studies & LSCS in percentage \\
\hline Casey et $\mathrm{al}^{2}$ & $51 \%$ \\
\hline Chandra $\mathrm{P}$ et $\mathrm{al}^{12}$ & $76.92 \%$ \\
\hline Sriya $R$ et al ${ }^{13}$ & $43.05 \%$ \\
\hline Present Study & $48 \%$ \\
\hline
\end{tabular}

If there is fetal distress, the treatment modality for such a situation is same everywhere, i.e. LSCS for delivery of the fetus, in shortest possible time. The incidence of LSCS is high, as it is widely accepted as the last resort to deliver the fetus, as early as possible to decrease the morbidity and mortality. The increment is also because of the antecedent and intranatal situations.

Table 33: Comparison of sensitivity, specificity, positive predictive value and negative predictive value.

\begin{tabular}{|lcc|c|}
\hline Parameters & $\begin{array}{c}\text { Baron et } \\
\text { al }^{16}\end{array}$ & $\begin{array}{r}\text { Chandra } \\
\text { et al }^{12}\end{array}$ & $\begin{array}{c}\text { Present } \\
\text { study }\end{array}$ \\
\hline Sensitivity & $78 \%$ & $76.92 \%$ & $68 \%$ \\
\hline Specificity & $74 \%$ & $73 \%$ & $60 \%$ \\
\hline $\begin{array}{l}\text { Positive } \\
\text { Predictive }\end{array}$ & $33 \%$ & $50 \%$ & $48 \%$ \\
$\begin{array}{l}\text { Value } \\
\text { Negative } \\
\text { predictive } \\
\text { value }\end{array}$ & $95 \%$ & $99 \%$ & $78 \%$ \\
\hline
\end{tabular}

The condition of oligohydramnios (AFI $<5 \mathrm{~cm}$ ), creating a situation causing fetal distress and requirement of LSCS had predictive effect, with a sensitivity of $68 \%$ and negative predictive value of $78 \%$. But the specificity and positive predictive value were poor. So this can be considered as a screening test for occurrence of fetal distress in intra-partum period requiring cesarean delivery.

The rate of LSCS was more in those with oligohydramnios and non-reactive NST (63.15\%). Even with reactive NST $(38.7 \%)$, patients develop fetal distress and LSCS was done and result was comparable to Kumar et al study. In control group, women with non-reactive NST had $50 \%$ cesarean rate and with reactive NST had only $5 \%$ of cesarean rates.

The mean birth weight is less in oligohydramnios group. The occurrence of low birth weight is $60 \%$ which is comparable with other studies (Chandra P et al $61.53 \%$ and Sriya $\mathrm{R}$ et al $58.38 \%$ ). In our study, 20 hypertensive patients were un-booked and poorly treated, as early detection could not be done. The high incidence of low birth weight, is likely due to chronic placental insufficiency, causing fetal growth restriction. The remaining cases of newborn, with low birth weight, oligohydramnios was the only pathological entity, that could have restricted the growth.

Table 34: Birth weight $<2.5 \mathrm{~kg}$.

\begin{tabular}{|c|c|}
\hline Studies & $\begin{array}{l}\text { Occurrence of birth } \leq 2.5 \\
\mathrm{~kg} \text { in percentage }\end{array}$ \\
\hline Casey et $\mathrm{al}^{2}$ & $35 \%$ \\
\hline Chandra $\mathrm{P}$ et al ${ }^{12}$ & $61.53 \%$ \\
\hline Sriya $\mathrm{R}$ et al ${ }^{13}$ & $58.38 \%$ \\
\hline Present Study & $60 \%$ \\
\hline
\end{tabular}

Table 35: Comparison of admission to neonatal intensive care unit (NICU).

\begin{tabular}{|c|c|}
\hline Studies & $\begin{array}{l}\text { Admission to NICU in } \\
\text { percentage }\end{array}$ \\
\hline Magann et al ${ }^{17}$ & $7.6 \%$ \\
\hline Casey et $\mathrm{al}^{2}$ & $7 \%$ \\
\hline Chandra $\mathrm{P}$ et al ${ }^{12}$ & $46.15 \%$ \\
\hline Sriya $\mathrm{R}$ et $\mathrm{al}^{13}$ & $88.88 \%$ \\
\hline Present study & $40 \%$ \\
\hline
\end{tabular}

$40 \%$ newborns were admitted in neonatal intensive care unit for various morbidities like neonatal seizures, birth asphyxia, meconium aspiration etc. This is not consistent with studies by Magann et al and Casey et al. However, both authors refer to admission to neonatal intensive care units. Reasons of these remarkable results were not expressed in the report. Study by Sriya $\mathrm{R}$ et al showed even higher incidence of (88.88\%) admission to neonatal intensive care unit.

All the 8 deaths in present study group were early neonatal deaths and were un-booked cases. Four of them died, due to Meconium Aspiration Syndrome with Early Onset of Sepsis. Two died of Severe Birth Asphyxia and the other two, with IUGR, died of Severe Respiratory Distress Syndrome. In control group, 2 neonatal deaths were due to meconium aspiration syndrome with severe birth asphyxia.

Meconium-stained amniotic fluid is really worrisome, from both the obstetrician's and the pediatrician's point of view, as it causes intranatal asphyxia, and increases the caesarean rates. Birth asphyxia due to Meconium Aspiration Syndrome results in increase in neonatal intensive care unit admissions.

Deliveries complicated with meconium-stained amniotic fluid are associated with increased operative delivery incidence, \& additional morbidity, in pregnancy outcomes. Thin meconium could be present in post term pregnancy. But Passage of thick meconium suggests severity, due to prolonged hypoxia. Along with oligohydramnios, risk factors include Placental insufficiency, maternal hypertension and preeclampsia. 
If antenatal complication, like preeclampsia is present in third trimester, it increases the possibility of development of oligohydramnios. Hypoxia due to utero-placental insufficiency results in reflex redistribution of fetal cardiac output i.e., renal and pulmonary blood flow decreases, leading to decreased urine production and lung secretion and hence decrease in amniotic fluid. This can initiate the whole situation leading to increased fetal morbidity and mortality.

\section{CONCLUSION}

Normal quantity of liquor amnii is essential for normal and successful outcome of pregnancy, as it provides a safe milieu interior for the foetus in utero. Excess of anything can be bad, and so also of liquor amnii. Simultaneously, deprivation of required quantity, will also adversely affect the neonatal outcome. Oligohydramnios, in itself is enough to cause such damage, by creating chronic hypoxic situation.

The fetal morbidity and mortality increases if additional antenatal complications of preeclampsia and post-term pregnancy are present along with oligohyrdramnios.

Preeclampsia and post-term are already antecedent situations, which cause chronic hypoxia due to different pathophysiology, causing foetal morbidity. Now, when it co-exists with oligohydramnios, hypoxia is aggravated due to increase in intrauterine pressure. Compressive effect of the uterine wall increases in labour. With increasing duration and intensity of the contractions, there will be temporary reduction of the blood supply, which aggravates the previous hypoxia which foetus is already subjected to. This will further decrease the oxygen supply. It increases the intra-natal and postnatal morbidity of foetus. Different grades morbidity of variable severity occurs, which may culminate in mortality.

Of all these antenatal conditions, it is not possible to forecast oligohydramnios.

As against that, Preeclampsia can be predicted, as well as, treated with vigilant and effective treatment. If done so, this will decrease intra-natal morbidity and mortality. Different advices, which partially, or completely,were ineffective to give a reasonable and long lasting effect, to avoid or circumvent the deleterious effect of oligohydramnios, were of no use.

So, we have only one thing, we can do, to reduce foetal morbidity keep good and vigilant antenatal check-up to diagnose the onset of preeclampsia and treat it adequately and vigilantly, and be on the constant outlook for the liquor quantity in last trimester.

Though, it is not possible to prevent the idiopathic oligohydramnios, if it is possible to detect other foetal reasons causing oligohydramnios, one can take a preventive or curative steps, if possible, with a reasonable certainty of good neonatal outcome.

Funding: No funding sources

Conflict of interest: None declared

Ethical approval: The study was approved by the Institutional Ethics Committee

\section{REFERENCES}

1. Phelan JP, Smith CV, Broussard P, Small M. Amniotic fluid volume assessment with the fourquadrant technique at 36-42 weeks' gestation. J Reprod Med. 1987;32:540-2.

2. Casey BM, MC Intire DD, Donald D. Pregnancy outcome after diagnosis of oligohydramnios at or beyond 34 weeks of gestation. Am J Obstet Gynecol. 2000;182:902-12.

3. Magann EF, Chauhan SP, Barrilleaux PS, Whitworth NS, Martin JN. Amniotic fluid index and single deepest pocket: Weak indicators of abnormal amniotic volumes. Obstet Gynecol. 2000;96:737-40.

4. Manning FA, Hill LM, Platt LD. Quantitative amniotic fluid volume determination by ultrasound: Antepartum detection of intrauterine growth retardation. Am J Obstet Gynecol 1981;139:254-8.

5. Halperin ME, Fong KW, Zalev AH. Reliability of amniotic fluid volume estimation from ultrasonograms: intra-observer and interobserver variation before and after the establishment of criteria. Am J Obstet Gynecol. 1985;153:264-7.

6. Brace RA, Wolfe EJ. Normal amniotic fluid volume changes throughout pregnancy. Am J Obstet Gynecol. 1989;161:382-8.

7. Manning FA, Harmon CR, Morrison I. Fetal assessment based on fetal biophysical profile scoring. IV> An analysis of perinatal morbidity and mortality. Am J Obstet Gynecol. 1990;162:703-9.

8. Moore TR, Cayle JE. The amniotic fluid index in normal human pregnancy. Am J Obstet Gynecol. 1990;162:1168-73.

9. Jeng CJ, Lee JF, Wang KG. Decreased amniotic fluid index in term pregnancy: clinical significance. $\mathrm{J}$ reprod Med. 1992;37:789-92.

10. Magann EF, Nolan TE, Hess LW. Measurement of amniotic fluid volume: accuracy of ultrasonography techniques. Am J Obstet Gynecol. 1992;167:1533.

11. Horsager R, Nathan L, Leveno KJ. Correlation of measured amniotic fluid volume and sonographic predictions of oligohydramnios. Obstet Gynecol. 1994;83:955.

12. Chandra P, Kaur SP, Hans DK, Kapila AK. The impact of amniotic fluid volume assessed intrapartum on perinatal outcome. Obstet and Gynae Today. 2000;5(8):478-81.

13. Sriya R, Singhai S. Perinatal outcome in patients with amniotic fluid index $<5 \mathrm{~cm}$. J Obstet and Gynaecol of India. 2001;51(5):98-100. 
14. Kumar P, Iyer S, Ramkumar V. Amniotic fluid index - A new ultrasound assessment of amniotic fluid. J Obstet and Gynaecol of India. 1991;41(1):10-2.

15. Rutherford SE, Jeffrey $P$, Phelan J, Smith CV, Jacobs N. The four quadrant assessment of amniotic fluid volume: An adjunct to antepartum fetal heart rate testing. Obstet Gynecol. 1987;70:353.

16. Baron C, Morgan MA, Garite TJ. The impact of amniotic fluid volume assessed intrapartum on perinatal outcome. Am J obstet Gynecol. 1995;173(1):167-74.

17. Magann EF, Chauhan SP, Kinsella MJ, McNamara MF, Whitworth NS, Morrison JC. Antenatal testing among 1001 patients at high risk: The role of ultrasonographic estimate of amniotic fluid volume. Am J Obstet Gynecol. 1999;180:1330-6.

Cite this article as: Kaur P, Desai DA, Taraiya A. A study on the perinatal outcome in cases of oligohydramnios. Int J Reprod Contracept Obstet Gynecol 2016;5:98-109. 